\title{
Lifestyle Changes in Diet and Physical Activities after Group Education for Type 2 Diabetes- The Active Ingredient in the Education. A Qualitative Study
}

\author{
Lisbeth 0. Rygg1*, Audhild Lohre ${ }^{2}$, Ove Hellzen ${ }^{1,3}$ \\ ${ }^{1}$ Faculty of Nursing and Health Sciences, NORD University, Norway \\ ${ }^{2}$ Faculty of Teacher and Interpreter Education, NTNU, Trondheim, Norway \\ ${ }^{3}$ Department of Nursing, Mid-Sweden University, Sundsvall, Sweden \\ Email: ${ }^{*}$ lisbeth.o.rygg@nord.no, audhild.lohre@ntnu.no, Ove.Hellzen@miun.se
}

How to cite this paper: Rygg, L.O., Lohre, A. and Hellzen, O. (2017) Lifestyle Changes in Diet and Physical Activities after Group Education for Type 2 Diabetes-The Active Ingredient in the Education. A Qualitative Study. Open Journal of Nursing, 7, 11811195.

https://doi.org/10.4236/ojn.2017.710086

Received: September 28, 2017

Accepted: October 24, 2017

Published: October 27, 2017

Copyright $\odot 2017$ by authors and Scientific Research Publishing Inc. This work is licensed under the Creative Commons Attribution International License (CC BY 4.0).

http://creativecommons.org/licenses/by/4.0/

\section{(c) (i) Open Access}

\begin{abstract}
Background: Diabetes self-management education (DSME) for patients with type 2 diabetes requires efficient teaching methods that make patients want to change lifestyle in terms of their diabetes. The study looks at what may be the active ingredient in this DSME. Objective: To explore how participants in DSME, with an interactive learning method, experienced changes in relation to diet and physical activity. Method: We studied possible changes in diet and physical activity by semi-structured individual interviews of 16 participants attending DSME. Results: Before the DSME, the participants felt insecure about what to eat, and they expressed little interest in changing their physical activity. Just after the DSME, they were more optimistic about diet because they had learned how to interpret food labels and compose their meals. Furthermore, they had experienced the benefit of physical activity in relation to their blood glucose levels. Behavior changes appeared to persist the following half year. We discuss the findings in light of the principles of interactive learning. The participants experienced an effect of their behavior changes, and blood glucose measurement was used as a tool to gain control and reach a state of well-being. Conclusion: From being insecure about what to eat, the patients acquired knowledge to handle their diet through the DSME. They learned how to compose their meals and use physical activity to regulate their blood glucose. We suggest that the interactive learning used in the DSME was an active ingredient that led to changes in behavior and should be considered as an educational method in DSME for patient with type 2 diabetes.
\end{abstract}




\section{Keywords}

Behavior Change, Diabetes, Self-Management Education, Nursing, Quality Improvement, Qualitative Research, Teaching/Learning Strategies, Interactive Learning

\section{Introduction}

Diabetes is one of the most challenging health problems in the $21^{\text {st }}$ century and caused 4.6 million deaths in 2011 [1]. Four out of five persons with diabetes have type 2 diabetes [2]. Diabetes education has, however, been emphasized by several researchers as one of the cornerstones of effective diabetes care and can be necessary in order to improve patients' health status and quality of life [3]. This article reports how patients with type 2 diabetes experience changes in relation to diet and physical activity after participating in group-based self-management education (DSME) and discuss the active ingredient in the this DSME.

Living with diabetes affects everyday life. People with diabetes are exposed to different challenges, they have to make adjustments of living habits, and they experience self-reproach and fear about possible complications [4]. The patients' self-management is often influenced by their understanding of their disease [5] and at the time of diagnosis, it can be essential for the patient to obtain knowledge about the disease, diet, exercise, and how to measure blood glucose [6]. For patients with diabetes, most of their diabetes care and day-to-day decisions are self-management. Many studies have reported lower quality of life and greater psychosocial problems for people with diabetes [7]. Psychosocial problems may lead to poor adherence to recommended diet and exercise regimes [8].

Diabetes education has been emphasized by several researchers as one of the cornerstones of effective diabetes care and can be necessary in order to improve patients' health status and quality of life [9]. Research has shown that educational programs can be beneficial, and self-efficacy has been suggested as a strong motivation to make lifestyle changes and a prerequisite in reaching healthy functioning [10]. Information of both healthy eating and physical activity are crucial to achieve glycemic control [11]. An essential part of the information is that recommendations have to be considered within the context of the patients' needs, preferences, and tolerances [12].

A meta-analysis of interventions with individual or group based education in type 2 diabetes showed improvement in glycemic control in people who received self-care management treatments with a small advantage to intervention with an educational approach [13]. Further, a systematic review of group based DSME showed significant health outcomes [14]. Despite the fact that diabetes education has shown an effect on biomedical results and lifestyle changes, the effect might decrease over time.

Thus, there is still much that can be improved in the field of DSME for type 2 
diabetes. Increased knowledge about patients' experiences with participation in DSME and lifestyle changes after the DSME can give providers a better understanding of what may be important to emphasize in the education. The aim of this qualitative study was to explore how participants in DSME for patients with type 2 diabetes experienced changes in relation to diet and physical activity and what was the triggering learning method that influenced this change.

\section{Methods}

In this study, we used semi-structured individual interviews conducted in a hospital trust in central Norway. DSME for type 2 diabetes has been provided and gradually developed by the two hospitals in the trust since the early 1990s. Patients were referred to the DSME by their GPs of several reasons; they were newly diagnosed, they had difficulty regulating their blood sugar, and/or they expressed a desire to attend DSME.

\subsection{Participants}

We recruited participants by convenience sampling from seven different type 2 diabetes DSME groups. Before the DSME started, the program leaders informed the patients about the current study, and those willing to participate were contacted. Participants who were diagnosed with type 2 diabetes, was $>18$ years of age and had been to a GP consultation in the previous 3 years were included. There was no preset cut off level for A1C. Those who had attended a diabetes education program during the previous 12 months were excluded. 16 participants, eight women and eight men, were included in the study. The mean age was 56 years (range: 35 - 72 years). Eight participants were diagnosed within the past year. The remaining eight were diagnosed between 1 and 15 years. Ten out of the 16 subjects were using medication for type 2 diabetes. An overview of the participants is shown in Table 1.

\subsection{Data Collection}

We collected the data through 16 in-depth semi-structured individual interviews (20 - 40 minutes) at three points in time: the first before DSME, the second just after the DSME, and again after 6 months. Interviews were transcribed verbatim. In addition, notes were taken during the interviews. The participants were asked about main elements like "Can you tell about your everyday life living with diabetes", "Can you tell me about your everyday life with diabetes today, and how you cope with it after you attended the DSME". They were also asked to give information about what expectations they had for education, how they had used the advice given in the DSME, and what they had changed after participating.

The Intervention-Group-Based Self-Management Education (DSME) for Patients with Type 2 Diabetes

DSME [15] for patients with type 2 diabetes was conducted in two hospitals in the hospital trust in central Norway from November 2007 to May 2008. Each 
Table 1. Characteristics of the participants $(n=16)$. Values are number and percent of participants if not otherwise stated.

\begin{tabular}{|c|c|}
\hline \multicolumn{2}{|c|}{ Characteristics } \\
\hline Mean age (years) (range) & $56(35-72)$ \\
\hline Male & $8(50 \%)$ \\
\hline Living with spouse & $14(88 \%)$ \\
\hline \multicolumn{2}{|c|}{ Time since diagnosis } \\
\hline $0-5$ months & $5(31 \%)$ \\
\hline $6-11$ months & $3(19 \%)$ \\
\hline $1-4$ years & $2(13 \%)$ \\
\hline $5-10$ years & $3(19 \%)$ \\
\hline Over 10 years & $3(19 \%)$ \\
\hline \multicolumn{2}{|c|}{ Treatment } \\
\hline Lifestyle advice only & $6(38 \%)$ \\
\hline Tablets & $6(38 \%)$ \\
\hline Insulin & $3(19 \%)$ \\
\hline Tablets and Insulin & $1(6 \%)$ \\
\hline \multicolumn{2}{|c|}{ Employment } \\
\hline Employed & $11(69 \%)$ \\
\hline Disability insurance & $1(6 \%)$ \\
\hline Retired & $4(25 \%)$ \\
\hline
\end{tabular}

DSME group consisted of 8 to 10 participants. The DSME lasted for 15 hours distributed in three sessions. The DSME was led by experienced diabetes nurses with input from physicians, physiotherapists, and a lay person who shared her experiences of living and dealing with the challenges of diabetes. The DSME included information about type 2 diabetes and its complications, diet, physical activity, and metabolic control.

The teaching methods were lectures, skills training, interactive learning, and group discussions. In the lectures, introductory information was given along with time to answer questions. The participants received an overall view of the disease and information about what worsens it and how to prevent serious health problems. There was also a section of information about available medical treatment. Further, the benefit of self-monitoring blood glucose was discussed.

The participants learned about the recommended levels of blood glucose. In the interactive learning/skills training, the participants were taught to measure their blood glucose level before and after performing physical activities at the DSME like brisk walking for about half an hour and $4 \times 4$-interval training on spin bikes. Likewise, they measured their blood glucose level before and after eating their regular lunch. The interactive learning also included activities where the participants worked with allocating food into groups of high, medium, and 
low levels of carbohydrates and fats according to the food nutrition labels. They also had to prepare a weekly diet and plan food combinations that correspond with a good diabetes diet. The participants received responses from the educational personnel during these work processes.

In the DSME, there was also time for group discussion about the patients' experiences and questions arising. The content of the DSME was described in more detail in a previous publication [15].

\subsection{Data Analysis}

Data was analysed using qualitative content analysis with an inductive analysis strategy. The first step of the analysis was reading through all transcribed interviews several times to obtain an overall sense of the whole [16]. The text was then re-read and the meaning units related to the aim of the study was identified. The meaning units were carefully condensed keeping close to the text. Thereafter, we coded the meanings units into subcategories by using different colors and making sure, they still reflected the original text. The subcategories that had something in common were then merged together into categories. Categories were then discussed until consensus emerged.

To deal with trustworthiness, the analysis was validated by constant comparison with the original transcripts to make sure that the connection was evident. The qualitative analysis was done manually.

\subsection{Ethics Statement}

The study was approved by the Regional Ethical Committee in Central Norway, REK number 4.2005.1556, and the Norwegian Data Inspectorate, number 13587. Signed informed consent was collected from the participants before any interview took place.

\section{Results}

The findings revealed the participants' experiences before and after DSME in relation to diet and physical activity as fitting into one of three categories: "feeling insecure" before DSME; "optimism and incipient control" just after the DSME; and "life satisfaction and well-being" after six months.

\subsection{Feeling Insecure}

To live with diabetes was described as a kind of straitjacket, controlling their life. They felt trapped in a life that allowed few indulgences. The restrictions made them unsure about how they were living according to their diabetes. This had given them fear of long-term complications and shortened the life.

Narration of diet was often frequently recurrent. Before the DSME, participants expressed uncertainty about what they could buy and eat. Participants felt angry and despaired because they felt they could not enjoy a good meal, a snack, or participate in social gatherings. 
I want to learn more about diabetes and diet, yes. So I don't have to speculate so much. Like when I go to the store I say to myself, "I cannot eat this and I cannot buy that". And then I would buy sugar-free juice, but there was no juice without sugar because it is orange and fruit juice in it, right?. you know, the diet was a nightmare for me because I was so fond of potatoes, and now I sort of just eat half a potato, but now there are several that say it is not so. No, I think it might be easier, yes? (Female [F], 55 - 64)

Information about physical activity was not expected or expressed as a desired area of information of the DSME program, of two reasons: either they expressed coping with exercise or they had a range of excuses for not being physically active. The ones who were coping with exercise felt they were mastering the physical activity. The participants who said they were physically inactive had arguments for their inactivity. Others explained inactivity by being busy at work.

Concerning the information about self-monitoring of blood glucose (SMBG), none of the participants expressed any need for information, for three reasons: coping with this task, they let healthcare personnel take care of it, or they gave up because it was too exhausting or technically difficult.

\subsection{Optimism and Incipient Control}

Life in change was expressed after the DSME. Participants had discovered that the training had given them knowledge, threw the interactive teaching method, of how to take better control of their diabetes treatment. This had given them the feeling of optimism and being able to live well with their diabetes.

Yes, composition of the diet was very important for me, as I told you earlier; the doctors knew nothing when it came to diabetes and diet. I was approximately at stage zero when I started the education. However, that was not the case when I completed. (F, 35 - 44)

The participants seemed more relaxed after the DSME. Self-monitoring of blood glucose was discovered as a management tool to control the effect of their actions. The participants used SMBG to see what level of blood glucose they gained by the different food they were eating.

...so we measured sugar before and after, you know. And it went all the way down, you know. It fell enormously you know... I was so surprised it (spinning) had such good effect. It surprised me. So now when I've eaten too much I jump on my bike and bicycles for a while. (Male [M], 35 - 44)

Physical activity was emphasized as an effective way of lowering their level of blood glucose, and they began focusing on increasing their physical activity.

\subsection{Life Satisfaction and Well-Being}

Six months after the DSME, the participants felt to have gained a feeling of coping with their diabetes. The DSME had given them the freedom of choice in how 
to live well. Participants even expressed that their lives had improved compared to before they were diagnosed.

Before, as I do now, I worked from 7:00-7:30 in the morning until 9:00-10:00 every night and there was not always time to take breaks to eat lunch or something. Therefore, I bought hot dogs and fast foods like that during the day. I do not do that anymore. I work just as much, but I have a different diet now and then I have much more energy. Now I am more conscious of what I am eating. Before the diabetes diagnosis, I could drink a glass of Coca Cola instead of eating. I drank around 4 - 5 liters a day. (M, 45 - 54)

Confidence in living with their diabetes was expressed by the participants. After the DSME, several of the participants expressed they knew what food to buy, and the time they spent grocery shopping had become increasingly shorter. The DSME had given the participants skills in managing their diet. They also felt more confident in social settings.

Six months after the DSME the participants still exercised, to lower an existing high blood sugar level or as prevention before social gatherings.

And if you are asked out in the evening or going to a party, then I measure my blood sugar before I leave. And if I'm high, a little over 7, I take a jog or run myself down a bit. (M, 45 - 54).

Gaining a certain control in their diabetes self-management gave the participants a feeling of coping and determination.

As the patients themselves handle most of the treatment for type 2 diabetes, taking responsibility for their self-management seemed affordable and adequate.

\section{Discussion}

In this article, we explored how participants in DSME for patients with type 2 diabetes experienced changes in relation to diet and physical activity. Our main findings showed that most of the participants experienced that their life with diabetes changed from being a life with insecurity and restricted personal freedom to a life with more control and increased well-being in their everyday living. It appeared clearly that the insecurity of living with diabetes was very current before the DSME. Just after completed DSME, it was revealed optimism and incipient control with living with their diabetes, while six months after completed DSME, life satisfaction and well-being was found (Table 2).

\subsection{Trajectories toward Better Self-Management}

From the data gathered before, just after, and again six months after the DSME, we saw the participants' experiences as steps in the trajectories of changes.

\subsubsection{The Insecure Life before DSME}

Several participants described living with diabetes as a life with many dietary restrictions but without much opportunity for indulgences. They experienced this 
Table 2. Summary of the analysis.

\begin{tabular}{ll}
\hline Subcategories & Categories \\
\hline Information about diet & \\
Information about physical activity & Before DSME: Feeling insecure \\
Information about self-monitoring of blood glucose & \\
Food nutrition labels & \\
Food combination-weekly diet plan & Just after the DSME: Optimism and \\
Self-monitoring of blood glucose & incipient control \\
Physical activity & \\
Coping/mastery & \\
Confidence & $\begin{array}{l}\text { Six months after DSME: Life satisfaction } \\
\text { and well-being }\end{array}$ \\
Responsibility for own illness & \\
\hline
\end{tabular}

as restrictions on their everyday life. We also found that their uncertainty about diet triggered feelings of insecurity in living with diabetes, and several of the participants expressed difficulties in maintaining adequate self-management and that they did not benefit sufficiently from regular care.

The participants' experiences of living with diabetes is in line with other studies reporting diabetes as a disease that can disrupt and limit patients' lives and change a person's identity and how they look at themselves [4] [7] [17]. It is a disease that can be difficult to control [7], and the glycemic management of the disease is complex [12]. Micro- and macrovascular complications may be the consequences of the disease [18] [19], which gives fear of the disease's consequences to some [17].

A lack of knowledge of a specific diet plan is a frequently reported barrier, with many patients experiencing difficulties in maintaining adequate self-management and not benefiting enough from regular care given from their GP [19] [20]. Much of the patients' treatment is in addition to medical treatment from the public health service, based on a high degree of self-management in form of day-to-day control and regulation of their condition [20]. Knowledge of the disease and its treatment is necessary, and insufficient information may lead to insecurity in living with the disease [21].

Altogether, this shows that there is a great need for knowledge and guidance on how to live with diabetes, which is also reflected in The American Diabetes Association's Standards of Medical Care, 2014, who states that patients should have an individualized treatment plan which recognizes diabetes self-management education [22]. The DSME in this study provided knowledge and skills for the self-management of diabetes, and gave most of the participants' insight into how to take control and regulate their blood glucose level.

\subsubsection{The Optimism of Better Self-Management from DSME}

During the DSME, several of the participants had managed to make some 
changes in their lifestyle, and their new routines were not seen as difficult to take hold of and perform. The changes were rather looked upon as desired and liberating actions to enable management of their everyday life with diabetes. The participants in our study reported that they used physical activity both to support dietary changes and to control their blood glucose levels. For example, one woman discovered how much her blood glucose was lowered when she increased the intensity of the physical activities she was performing at the DSME, which made her understand how physical activity affected her blood glucose. Also, several of the participants spent much time reading food labels when they was shopping for food, especially just after the DSME, and they started to measure their blood glucose level after eating different kinds of foods to understand how much foods affected the level of sugar in their blood. This provided fertile ground for optimism and increased control in their self-management of diabetes. Using diet and exercise is among the actions people use for achieving the goal of well-regulated blood glucose [23].

Thus, to make changes both in diet and in physical activity the participants used knowledge gained in the DSME. Likewise, other researchers have reported benefits of group-based education for type 2 diabetes [24]. In accordance with our findings, a study by Malpass et al. found that patients newly diagnosed with type 2 diabetes who received diet and physical activity information together thought that making multiple lifestyle changes were helpful rather than problematic [11]. Further, several studies have reported great health benefits related to changes in diet and increased activity, like improved glycemic control, a decrease in cardiovascular risk factors [25] [26], improvements in physical mobility [27], reduced weight, reduced use of medicine, and reduced rate of sleep apnea [28].

\subsubsection{Greater Confidence and Well-Being after DSME}

Six months after the DSME, many of the participants reported that their life with diabetes had become better. They expressed gained confidence and coping with their diabetes, which had given them increased well-being and life satisfaction. People experiencing well-being when their lives unfold can see their world in a different way [29]. A meta-analysis shows that people with diabetes experience improved quality of life from participation in diabetes self-management training programs [30]. Knowledge, taking responsibility for their own health, and receiving confirmation of an already healthy lifestyle is found to be factors essential for making lifestyle changes following DSME. Motivating factors for maintaining lifestyle changes are support from others, experiencing an effect of their lifestyle changes, fear of complications, and that lifestyle changes becoming a habit and a part of their life [24].

Life satisfaction and well-being seem to be linked to having freedom of choice in the diabetes diet, having a feeling of control, and being able to cope with the illness. Studies examining quality of life in diabetic patients show that areas that involve freedom to eat what they want, feelings about their future, and self-confidence are areas that affect their quality of life in living with diabetes 
[31]. To find an approach to the DSME that develops the patients' coping and confidence in their daily life with diabetes and enable them to have dietary freedom and flexibility apparently may improve their life satisfaction and well-being. The teaching method in this study intervention seems to have achieved this.

\subsection{How to Understand the Changes in the Trajectories}

To what degree people follow guidance in terms of diet and physical activity may be determined by how they look at their diabetes and their understanding of taking responsibility for their own health [24]. Several barriers in lifestyle changes for patients with type 2 diabetes have been found, including difficulties in changing well-established habits, negative perception of the "new" or recommended regimen, lack of knowledge and understanding, lack of motivation, barriers relating to the practicalities of making lifestyle changes, ineffective multidisciplinary approaches, and communication [32] [33].

Skills, confidence, and the ability to make decisions on a day-to-day basis about the treatment and lifestyle are parts of the management of type 2 diabetes, and the consequences of these decisions affect a person's health [34]. Although many diabetes guidelines state this, the reality differs for many people with diabetes. This means that not everyone who is diagnosed with diabetes type 2 receives proper information and education. The intervention with interactive learning in the DSME in our study seems to have been an agent that gave the participants a key to start mastering the disease.

\section{Interactive Learning}

By interactive teaching, healthcare professionals can support the acquisition of necessary knowledge [35]. Sims suggested four dimensions in which interactive learning may be characterized [35]. First, the Learner, the "who" in the learning process, was presented. Next the Content, the "what", and the Pedagogy, the "how", and as the fourth dimension, the Context, the "when" and "where", were described. In the present study, all four dimensions are included, but they are not easily seen as separated dimensions. Therefore the participants (the learners), the tasks in the course (the content), the teaching principles (pedagogy), and the places (the where) are discussed interwoven in each other. In interactive teaching, the participants are able to experience the result of the practical actions they perform with support of the educators. In our study, such support was given in the cultural context of studios with bicycling and in walking tours outside. Further, the participants saw an effect of what they did. They experienced physical activity as an effective tool for reducing their blood sugar, and they began to use physical activity before eating to keep their blood sugar levels at an acceptable level. Also, the participants learned to see the effect of different foods on their blood glucose. They started to use blood glucose measurements as a monitoring tool for the blood glucose effect of different foods. This gave them confidence in relation to the intake of food. In line with our observations, self-management of blood glucose has been indicated to empower patients by its 
feedback [36] [37] and to motivate to lifestyle changes [38]. Even though SMBG is a recommended element in education for the self-management of type 2 diabetes [37] [39] there is no general consensus on the effect of SMBG [37] [40] [41]. On the contrary, there is a continuing debate that also includes increased healthcare costs [41] [42]. For the patient, the SMBG has several purposes. In addition to being a confirmation of low or high blood glucose levels, the measurement may indicate effects of interventions like diet and exercise and motivate healthy behavior, in accordance with our findings.

Further, in studying effects of DSME, structural characteristics are often discussed. It has been found that more hours of education (19 to 52 hours) spread over a period of 6 to 10 months or with many sessions ( 6 to 10 sessions) tended to do better than education with shorter durations [14]. Other studies report a higher effect in education that is compact with meetings closely grouped together [13]. One systematic review reported that education delivered by several educators may improve the effect of education [43], while another review found that only one educator tended to do better than having a group of educators in the educations [14].

Only a few studies have explored what may be a functional "active ingredient" in group-based education for type 2 diabetes. Our study suggests that the interactive learning with "hands on activities" together with SMBG may be the active ingredient in the present intervention. The participants were motivated before the course or became motivated toward lifestyle changes during the course. They did practical exercises, and the SMBG helped them to see effects of what they did. The importance of "doing" is supported by a small study among Latino people with diabetes and low literacy [44] and also, by the much sited article by of Trento and colleagues [45].

\section{Study Limitations and Strengths}

There are several limitations to this study. The interviews took place in an area that was restricted geographically because of the fact that the interviews were conducted in only one hospital trust in central Norway. The follow-up of six months may have been too short in terms of lifestyle changes, which have been shown to be difficult to maintain beyond six months [46]. Gender differences may also be a bias in this study because men compared to women, may have lower skills or less self-efficacy in mandatory diabetes expertise as food and household management. Social reporting is also a subject to bias. How we sample the participants, how we extracts during the analysis and decides who and what to quote, all involves the decision about whose voices will be heard [47]. A strength of the study is that the participants were recruited from five different diabetes education groups during a five-month period. There were participants included from different municipals both in rural and city areas. The participants differed in gender, age, time since diagnosis, and type of medication and treatment. 


\section{Conclusion and Implications for Practice}

In this study, we explored the changes in diet, physical activity among 16 participants attending an education program for type 2 diabetes. We also explored what was the triggering learning method that influenced this change. The participants were interviewed at three points in time: before and just after DSME and six months later.

From being insecure about what to eat, the patients acquired knowledge to handle their diet through the course. Moreover, they learned how to use physical activity to regulate their blood glucose. This shows that patients who attend a DSME can experience improvement in their life satisfaction and wellbeing.

Measuring their blood glucose before and after food intake or physical activity showed the participants the effect of their efforts. This insight was especially interesting to observe in those who clearly expressed no need of doing changes in physical activity before the course. We suggest that the interactive learning used in the course was an active ingredient that led to changes in behavior.

By understanding the trajectory of the patients, nurses can ease patients' self-management process and thus decrease suffering and economic costs. Interactive learning including blood glucose measurement should be considered in education programs for type 2 diabetes.

\section{Funding}

This work was supported by the Central Norway Health Authorities, Samarbeidsorganet [grant number 46011600-47].

\section{Authors' Contributions}

Conceived and designed the study: LOR. Performed the study: LOR. Analyzed the data: $\mathrm{LOR}, \mathrm{AL}, \mathrm{OH}$. Wrote the paper: $\mathrm{LOR}, \mathrm{AL}, \mathrm{OH}$.

\section{References}

[1] IDF IDF (2011) Diabetes Atlas. 5th Edition.

[2] Horton, E.S. (2008) Can Newer Therapies Delay the Progression of Type 2 Diabetes Mellitus? Endocrine Practice, 14, 625-638. https://doi.org/10.4158/EP.14.5.625

[3] Funnell, M.M. and Weiss, M.A. (2009) Empowering Patients with Diabetes. Nursing, 39, 34-37. https://doi.org/10.1097/01.NURSE.0000347073.76891.2a

[4] Manderson, L. and Kokanovic, R. (2009) "Worried All the Time": Distress and the Circumstances of Everyday Life among Immigrant Australians with Type 2 Diabetes. Chronic Illness, 5, 21-32. https://doi.org/10.1177/1742395309102243

[5] Hornsten, A., Sandstrom, H. And Lundman, B. (2004) Personal Understandings of Illness among People with Type 2 Diabetes. Journal of Advanced Nursing, 47, 174-182. https://doi.org/10.1111/j.1365-2648.2004.03076.x

[6] Peel, E., Parry, O., Douglas, M. and Lawton, J. (2004) Diagnosis of Type 2 Diabetes: A Qualitative Analysis of Patients' Emotional Reactions and Views about Information Provision. Patient Education \& Counseling, 53, 269-275. https://doi.org/10.1016/j.pec.2003.07.010 
[7] Pera, P.I. (2011) Living with Diabetes: Quality of Care and Quality of Life. Patient Prefer Adherence, 5, 65-72.

[8] Peyrot, M., Rubin, R.R., Lauritzen, T., et al. (2005) Psychosocial Problems and Barriers to Improved Diabetes Management: Results of the Cross-National Diabetes Attitudes, Wishes and Needs (DAWN) Study. Diabetic Medicine, 22, 1379-1385. https://doi.org/10.1111/j.1464-5491.2005.01644.x

[9] Haas, L., Maryniuk, M., Beck, J., et al. (2014) National Standards for Diabetes Self-Management Education and Support. Diabetes Care, 37, S144-S153. https://doi.org/10.2337/dc14-S144

[10] Deakin, T., McShane, C.E., Cade, J.E. and Williams, R.D. (2005) Group Based Training for Self-Management Strategies in People with Type 2 Diabetes Mellitus. The Cochrane Database of Systematic Reviews, 2, Cd003417. https://doi.org/10.1002/14651858.CD003417.pub2

[11] Malpass, A., Andrews, R. and Turner, K.M. (2009) Patients with Type 2 Diabetes Experiences of Making Multiple Lifestyle Changes: A Qualitative Study. Patient Education and Counseling, 74, 258-263. https://doi.org/10.1016/j.pec.2008.08.018

[12] Inzucchi, S.E., Bergenstal, R.M., Buse, J.B., et al. (2012) Management of Hyperglycemia in Type 2 Diabetes: A Patient-Centered Approach: Position Statement of the American Diabetes Association (ADA) and the European Association for the Study of Diabetes (EASD). Diabetes Care, 35, 1364-1379. https://doi.org/10.2337/dc12-0413

[13] Minet, L., Moller, S., Vach, W., Wagner, L. and Henriksen, J.E. (2010) Mediating the Effect of Self-Care Management Intervention in Type 2 Diabetes: A Meta-Analysis of 47 Randomised Controlled Trials. Patient Education and Counseling, 80, 29-41. https://doi.org/10.1016/j.pec.2009.09.033

[14] Steinsbekk, A., Rygg, L.O., Lisulo, M., Rise, M.B. and Fretheim, A. (2012) Group Based Diabetes Self-Management Education Compared to Routine Treatment for People with Type 2 Diabetes Mellitus. A Systematic Review with Meta-Analysis. BMC Health Services Research, 12, 213. https://doi.org/10.1186/1472-6963-12-213

[15] Rygg, L.O., Rise, M.B., Gronning, K. and Steinsbekk, A. (2012) Efficacy of Ongoing Group Based Diabetes Self-Management Education for Patients with Type 2 Diabetes Mellitus. A Randomised Controlled Trial. Patient Education and Counseling, 86, 98-105. https://doi.org/10.1016/j.pec.2011.04.008

[16] Graneheim, U.H. and Lundman, B. (2004) Qualitative Content Analysis in Nursing Research: Concepts, Procedures and Measures to Achieve Trustworthiness. Nurse Education Today, 24, 105-112. https://doi.org/10.1016/j.nedt.2003.10.001

[17] Olshansky, E., Sacco, D., Fitzgerald, K., et al. (2008) Living with Diabetes: Normalizing the Process of Managing Diabetes. The Diabetes Educator, 34, 1004-1012. https://doi.org/10.1177/0145721708327304

[18] Gu, K., Cowie, C.C. and Harris, M.I. (1998) Mortality in Adults with and without Diabetes in a National Cohort of the U.S. Population, 1971-1993. Diabetes Care, 21, 1138-1145. https://doi.org/10.2337/diacare.21.7.1138

[19] Fabre, J., Balant, L.P., Dayer, P.G., Fox, H.M. and Vernet, A.T. (1982) The Kidney in Maturity Onset Diabetes Mellitus: A Clinical Study of 510 Patients. Kidney International, 21, 730-738. https://doi.org/10.1038/ki.1982.90

[20] Nagelkerk, J., Reick, K. and Meengs, L. (2006) Perceived Barriers and Effective Strategies to Diabetes Self-Management. Journal of Advanced Nursing, 54, 151-158. https://doi.org/10.1111/j.1365-2648.2006.03799.x 
[21] Rygg, L.O., Rise, M.B., Lomundal, B., Solberg, H.S. and Steinsbekk, A. (2010) Reasons for Participation in Group-Based Type 2 Diabetes Self-Management Education. A Qualitative Study. Scand J Public Health, 38, 788-793. https://doi.org/10.1177/1403494810382475

[22] American Diabetes Association (2014) Standards of Medical Care in Diabetes2014. Diabetes Care, 37, S14-S80. https://doi.org/10.2337/dc14-S014

[23] Rosenbek Minet, L.K., Lonvig, E.M., Henriksen, J.E. and Wagner, L. (2011) The Experience of Living with Diabetes Following a Self-Management Program Based on Motivational Interviewing. Qualitative Health Research, 21, 1115-1126. https://doi.org/10.1177/1049732311405066

[24] Rise, M.B., Pellerud, A., Rygg, L.O. and Steinsbekk, A. (2013) Making and Maintaining Lifestyle Changes After Participating in Group Based Type 2 Diabetes Self-Management Educations: A Qualitative Study. PLoS One, 8, e64009. https://doi.org/10.1371/journal.pone.0064009

[25] Wing, R.R., Lang, W., Wadden, T.A., et al. (2011) Benefits of Modest Weight Loss in Improving Cardiovascular Risk Factors in Overweight and Obese Individuals with Type 2 Diabetes. Diabetes Care, 34, 1481-1486. https://doi.org/10.2337/dc10-2415

[26] Wing, R.R. (2010) Long-Term Effects of a Lifestyle Intervention on Weight and Cardiovascular Risk Factors in Individuals with Type 2 Diabetes Mellitus: Four-Year Results of the Look AHEAD Trial. Archives of Internal Medicine, 170, 1566-1575.

[27] Rejeski, W.J., Ip, E.H., Bertoni, A.G., et al. (2012) Lifestyle Change and Mobility in Obese Adults with Type 2 Diabetes. The New England Journal of Medicine, 366, 1209-1217. https://doi.org/10.1056/NEJMoa1110294

[28] Kuna, S.T., Reboussin, D.M., Borradaile, K.E., et al. (2013) Long-Term Effect of Weight Loss on Obstructive Sleep Apnea Severity in Obese Patients with Type 2 Diabetes. Sleep, 36, 641-649a. https://doi.org/10.5665/sleep.2618

[29] Healey-Ogden, M.J. and Austin, W.J. (2011) Uncovering the Lived Experience of Well-Being. Qualitative Health Research, 21, 85-96. https://doi.org/10.1177/1049732310379113

[30] Cochran, J. and Conn, V.S. (2008) Meta-Analysis of Quality of Life Outcomes Following Diabetes Self-Management Training. The Diabetes Educator, 34, 815-823. https://doi.org/10.1177/0145721708323640

[31] Wang, H.F. and Yeh, M.C. (2013) The Quality of Life of Adults with Type 2 dIabetes in a Hospital Care Clinic in Taiwan. Quality of Life Research, 22, 577-584. https://doi.org/10.1007/s11136-012-0178-7

[32] Booth, A.O., Lowis, C., Dean, M., Hunter, S.J. and McKinley, M.C. (2013) Diet and Physical Activity in the Self-Management of Type 2 Diabetes: Barriers and Facilitators Identified by Patients and Health Professionals. Primary Health Care Research \& Development, 14, 293-306. https://doi.org/10.1017/S1463423612000412

[33] Dudley, B., Heiland, B., Kohler-Rausch, E. and Kovic, M. (2014) Education and Technology Used to Improve the Quality of Life for People with Diabetes Mellitus Type II. Journal of Multidisciplinary Healthcare, 7, 147-153. https://doi.org/10.2147/JMDH.S52681

[34] Jarvis, J., Skinner, T.C., Carey, M.E. and Davies, M.J. (2010) How Can Structured Self-Management Patient Education Improve Outcomes in People with Type 2 Diabetes? Diabetes, Obesity and Metabolism, 12, 12-19. https://doi.org/10.1111/j.1463-1326.2009.01098.x 
[35] Sims, R. (2000) An Interactive Conundrum: Constructs of Interactivity and Learning Theory. Australian Journal of Educational Technology, 16, 45-57.

[36] Leventhal, H., Benyamini, Y., Brownlee, S., Diefenbach, M., Leventhal, E.A., Patrick-Miller, L., et al. (1997) Illness Representations: Theoretical Foundations. In: Petrie, K.J. and Weinman, J., Eds., Perceptions of Health and Illness, Harwood Academic Publisher, Amsterdam.

[37] Klonoff, D.C., Blonde, L., Cembrowski, G., et al. (2011) Consensus Report: The Current Role of Self-Monitoring of Blood Glucose in Non-Insulin-Treated Type 2 Diabetes. Journal of Diabetes Science and Technology, 5, 1529-1548. https://doi.org/10.1177/193229681100500630

[38] Karter, A.J., Ackerson, L.M., Darbinian, J.A., et al. (2001) Self-Monitoring of Blood Glucose Levels and Glycemic Control: The Northern California Kaiser Permanente Diabetes Registry. American Journal of Medicine, 111, 1-9. https://doi.org/10.1016/S0002-9343(01)00742-2

[39] ADA (2010) Standards of Medical Care in Diabetes-2010. Diabetes Care, 33, S11-S61. https://doi.org/10.2337/dc10-S011

[40] Kempf, K., Tankova, T. and Martin, S. (2013) ROSSO-In-Praxi-International: Long-Term Effects of Self-Monitoring of Blood Glucose on Glucometabolic Control in Patients with Type 2 Diabetes Mellitus Not Treated with Insulin. Diabetes Technology \& Therapeutics, 15, 89-96. https://doi.org/10.1089/dia.2012.0213

[41] Malanda, U.L., Welschen, L.M., Riphagen, I.I., et al. (2012) Self-Monitoring of Blood Glucose in Patients with Type 2 Diabetes Mellitus Who Are Not Using Insulin. The Cochrane Database of Systematic Reviews, 1, Cd005060.

[42] Clar, C., Barnard, K., Cummins, E., Royle, P. and Waugh, N. (2010) Self-Monitoring of Blood Glucose in Type 2 Diabetes: Systematic Review. Health Technology Assessments, 14, 1-140. https://doi.org/10.3310/hta14120

[43] Loveman, E., Frampton, G.K. and Clegg, A.J. (2008) The Clinical Effectiveness of Diabetes Education Models for Type 2 Diabetes: A Systematic Review. Health Technology Assessments, 12, 1-116, iii. https://doi.org/10.3310/hta12090

[44] Carbone, E.T., Lennon, K.M., Torres, M.I. and Rosal, M.C. (2005) Testing the Feasibility of an Interactive Learning Styles Measure for U.S. Latino Adults with Type 2 Diabetes and Low Literacy. International Quarterly of Community Health Education, 25, 315-335. https://doi.org/10.2190/88J7-1432-2377-55K7

[45] Trento, M., Passera, P., Tomalino, M., et al. (2001) Group Visits Improve Metabolic Control in Type 2 Diabetes a 2-Year Follow-Up. Diabetes Care, 24, 995-1000. https://doi.org/10.2337/diacare.24.6.995

[46] Norris, S.L., Engelgau, M.M. and Narayan, K.M. (2001) Effectiveness of SelfManagement Training in Type 2 Diabetes: A Systematic Review of Randomized Controlled Trials. Diabetes Care, 24, 561-587. https://doi.org/10.2337/diacare.24.3.561

[47] Patton, M.Q. (2002) Qualitative Research \& Evaluation Methods. 3rd Edition, Sage Publications, Inc., Thousand Oaks, California. 